\title{
A Compact Tri-band Printed Antenna for MIMO Applications
}

\author{
Jiawei ZANG, Xuetian WANG \\ Dept. of Information and Electronics, Beijing Institute of Technology, 5 South Zhongguancun Street, Haidian District, \\ 100081 Beijing, China
}

jiaweizang@gmail.com, wangxuetian@bit.edu.cn

\begin{abstract}
In this paper, a compact tri-band printed multiinput multi-output (MIMO) antenna with high isolation is presented to operate within WLAN and WiMAX frequency bands. By adopting a rectangular open-ended slot combined with a rectangular strip with an inverted L-shaped open-ended slot, three operating frequency bands can be obtained. The proposed compact MIMO antenna occupies an overall size of $19 \times 33 \mathrm{~mm}^{2}$. Good port-to-port isolation is obtained. The simulated and measured results show that the presented antenna is suitable for multiband MIMO applications.
\end{abstract}

\section{Keywords}

Compact, MIMO antenna, printed antenna, tri-band antenna

\section{Introduction}

With the rapid development of wireless communication systems, antennas able to operate for wireless local area network (WLAN) and worldwide interoperability for microwave access (WiMAX) simultaneously are required in many applications. Recently, several multiband antennas have been reported to support these applications. In [1], three radiating strips are used to realize the triple bands to cover the WLAN/WiMAX frequency bands. In [2], an Hshaped slot antenna fed by microstrip coupling is presented to achieve multiband operation. A tri-band monopole antenna based on single-loop resonator (SLR) is reported in [3]. A coplanar waveguide (CPW)-fed dual band monopole antenna is proposed in [4], and the resonance location can be altered by changing the embedded slots at the radiating patch. In [5], a square spiral-patch is presented for multiband applications. The design of a dual-band dipole antenna loaded with U-shaped slots is given in [6].

On the other hand, small multipath fading, enhanced channel capability and high-quality data transmission in wireless communication systems are desirable and challenging. The MIMO antennas can be employed to enhance the capability. Therefore, MIMO antennas receive a great deal of attention. A metamaterial-based MIMO antenna is proposed in [7], and good ports isolation performance is achieved by adopting defected ground structure. A dual-band MIMO antenna is reported in [8], and high port isolation is achieved by adopting transmission lines and etching slots. In [9], three printed dipole antennas are placed orthogonal to each other to realize pattern diversity. In [10], authors present a compact MIMO antenna for ultra-wideband (UWB) applications. In [11], a quad-band four elements MIMO antenna is published, and the four antenna elements are arranged separately and orthogonal with each other to improve isolation. A tri-band E-shaped monopole antenna for WLAN application is presented in [12]. Two-element arrays of such antennas in different configurations are analyzed, but it occupies a large space. However, because of the limited space in some small electronic products, the mutual coupling between the antenna elements can be very large. Therefore, it remains a problem to design multiband MIMO antennas with compact structure and high isolation.

In this letter, a small size tri-band printed antenna, suitable for MIMO applications is presented. Two orthogonal feedings are used to excite the horizontal and vertical linear polarization simultaneously, which also ensure high port-to-port isolation and pattern diversity. The oversize of the proposed antenna is $19 \times 33 \mathrm{~mm}^{2}$. The open-ended rectangular slot is employed to obtain the $5.5 \mathrm{GHz}$ band, and the loaded rectangular strip is used to obtain the $2.4 \mathrm{GHz}$ band. Meanwhile, the $3.5 \mathrm{GHz}$ band is achieved with the use of inverted open-ended L-shaped slot.

Compared to the antennas in [1-12], our proposed antenna configuration not only achieves the triple bands simultaneously, but also has a rather simple and smaller structure which is easy to fabricate with low cost. What is more, our proposed antenna configuration also allows for the independent adjustment of each operating bands within certain limits, which is an important aspect for practical applications. Also, our proposed antenna offers high portto-port isolation and good diversity performance. Details of our proposed antenna design and the results are presented. 


\section{Antenna Design and Analysis}

The geometry of the proposed triple bands printed MIMO antenna is shown in Fig. 1. The proposed antenna is printed on a $1.0 \mathrm{~mm}$-thick FR4 dielectric substrate with relative permittivity of 4.4 and loss tangent of 0.02 . The antenna structure consists of two microstrip feeding lines, a slotted patch, and two via holes. A $50 \mathrm{Ohm}$ microstrip line is used to feed the antenna with its end connected to the slotted patch through a metallic via hole. This feeding method contributes to antenna miniaturization. This is because the current on the slotted patch will be redistributed. Compared to traditional microstrip feeding method (without shorting via), the feeding method used in this paper makes the currents flow along the open-ended rectangular slot much regularly and in phase. Therefore, a smaller antenna size can satisfy the desired resonant frequencies. Note that the two elements of the antenna are orthogonal with each other in order to achieve polarization diversity. It is worth to be mentioned that although the two elements share the whole ground plane, good ports isolation can also be realized. The proposed antenna is designed and optimized by using ANSYS HFSS. A series of optimization works are carried out to obtain the expected antenna performance. The final optimized dimensions of the proposed triple bands MIMO antenna for WLAN/WiMAX applications are described in Tab. 1.

More specifically, the design procedure is demonstrated in Fig. 2. The slotted patch starts by conventional

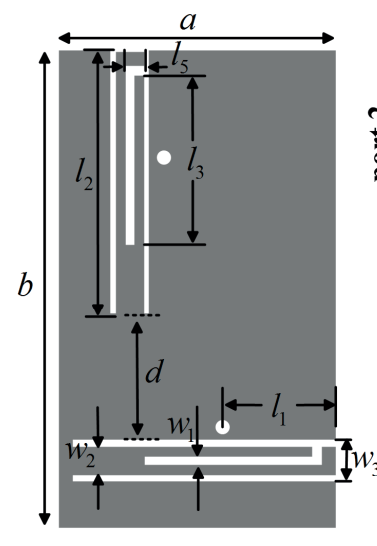

(a)

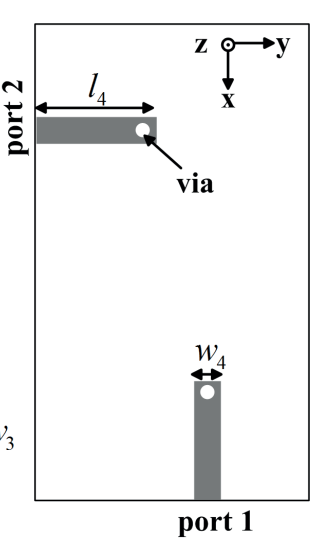

(b)
Fig. 1. Configuration of the proposed MIMO antenna: (a) top view, (b) bottom view.

\begin{tabular}{|c|c|c|c|}
\hline Parameters & $\begin{array}{c}\text { Dimensions } \\
(\mathrm{mm})\end{array}$ & Parameters & $\begin{array}{c}\text { Dimensions } \\
(\mathrm{mm})\end{array}$ \\
\hline$a$ & 19 & $l_{4}$ & 8.1 \\
\hline$b$ & 33 & $l_{5}$ & 1.1 \\
\hline$d$ & 8 & $w_{1}$ & 0.6 \\
\hline$l_{1}$ & 6.8 & $w_{2}$ & 2 \\
\hline$l_{2}$ & 16.9 & $w_{3}$ & 3.2 \\
\hline$l_{3}$ & 11.4 & $w_{4}$ & 1.8 \\
\hline
\end{tabular}

Tab. 1. Optimal dimensions of the designed antenna.

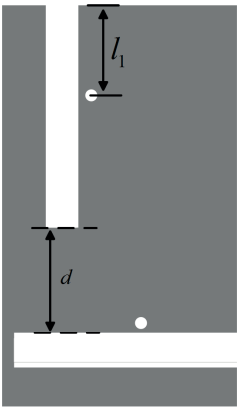

(a)

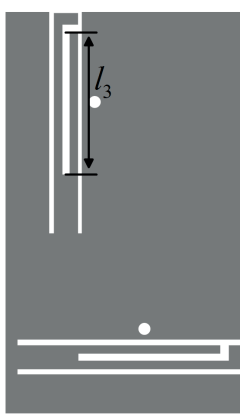

(c)

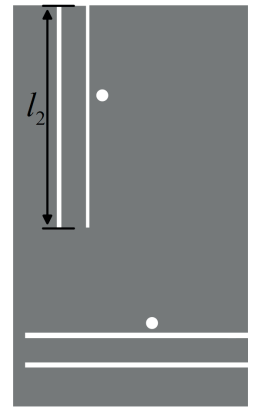

(b)

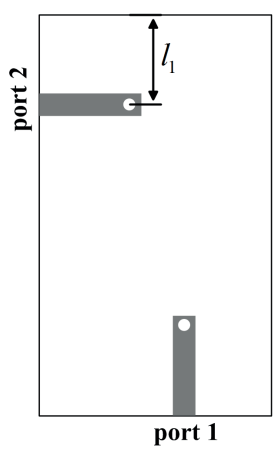

(d)
Fig. 2. Design procedure of the proposed tri-band MIMO antenna: (a) top view of the single-band antenna, (b) top view of the dual-band antenna, (c) top view of the tri-band antenna, (d) bottom view of the three antennas.

open-ended rectangular slot patch, which produces the $5.5 \mathrm{GHz}$ resonant mode (antenna of Fig. 2(a)). Based on the aforementioned radiation patch, a rectangular strip is loaded to obtain the resonant mode at $2.4 \mathrm{GHz}$ (antenna of Fig. 2(b)). Finally, a quarter-wavelength open-ended Lshaped slot is embedded in the rectangular strip to produce a current path at about $3.5 \mathrm{GHz}$ (antenna of Fig. 2(c)), and thus the proposed antenna can provide the expected triple frequency bands. It should be noted that the center frequencies of the $2.4,3.5$ and $5.5 \mathrm{GHz}$ bands can be easily adjusted by mainly changing the value of $l_{2}, l_{3}$ and $l_{1}$ respectively. This is because the length of the corresponding current path is changed with different values of $l_{2}, l_{3}$ and $l_{1}$. Therefore, the resonant frequency is altered. The proposed tri-band antenna has been investigated for its resonance characteristics by carrying out parametric studies with the variation of one parameter at a time, keeping other parameters fixed.

The simulated curves of S-parameters for different values of $l_{1}, l_{2}$ and $l_{3}$ are depicted in Fig. 3. Fig. 3(a) demonstrates the simulated S-parameters for different feeding position $\left(l_{1}\right)$ of antenna of Fig. 2(a). It can be seen, with the increasing of $l_{1}$, that the $5.5 \mathrm{GHz}$ band shifts to lower frequencies. Fig. 3(b) shows the variation of S-parameters for different values of $l_{2}$ of antenna of Fig. 2(b). With $l_{2}$ decreasing from 17.9 to $15.9 \mathrm{~mm}$, the center frequency of the $2.4 \mathrm{GHz}$ band changes from 2.4 to $2.7 \mathrm{GHz}$. At the same time, the impedance match of the $5.5 \mathrm{GHz}$ band becomes worse, but its center frequency remains unchanged. 
Fig. 3(c) shows the simulated S-parameters for different $l_{3}$ of antenna of Fig. 2(c). Note that the resonant frequency at $3.5 \mathrm{GHz}$ decreases when $l_{3}$ increases, while the other bands are almost constant. Parametric studies show that the three resonant modes can be tuned independently within certain limits. These features make the proposed antenna design a much simpler work. In fact, the same effect is observed for parameter $S_{22}$. The resonant frequencies of the two ports stay the same, although there is no symmetry between the two antenna elements with respect to their positions in the ground plane. Sure, the characteristics of impedance matching of the two ports at these three bands are different, but good impedance matching is still obtained. In addition, the feeding position, the length of loaded rectangular strip and L-shaped slot should be optimized to obtain the desired WLAN/WiMAX bands. Meanwhile, good port-to-port isolation is obtained as shown in Fig. 3. The simulated traces of S-parameters for different values of $d$ (the distance between antenna elements) are given in Fig. 4. We can find that the port-to-port isolation is enhanced when $d$ increases. However, the resonance properties of the triband antenna almost keep unchanged. That means the size of ground plane has little effect on antenna operating frequencies.

To better understand the mechanism of the tri-band MIMO antenna, the surface current distributions of the pro-

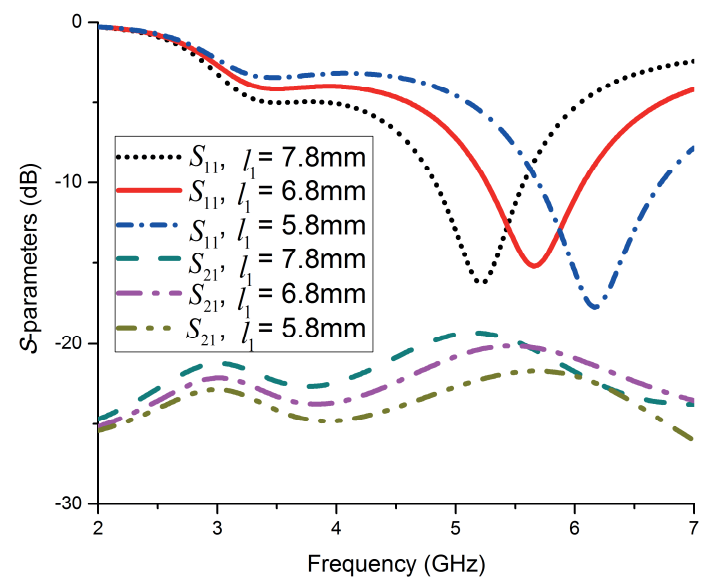

(a)

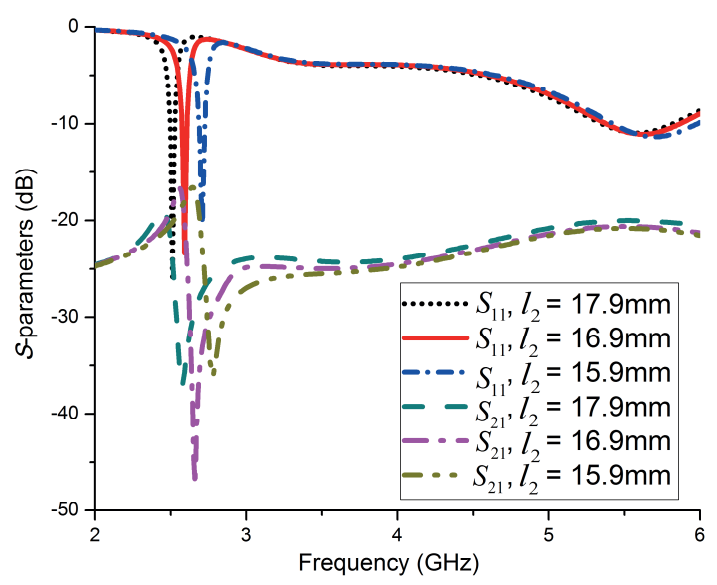

(b)

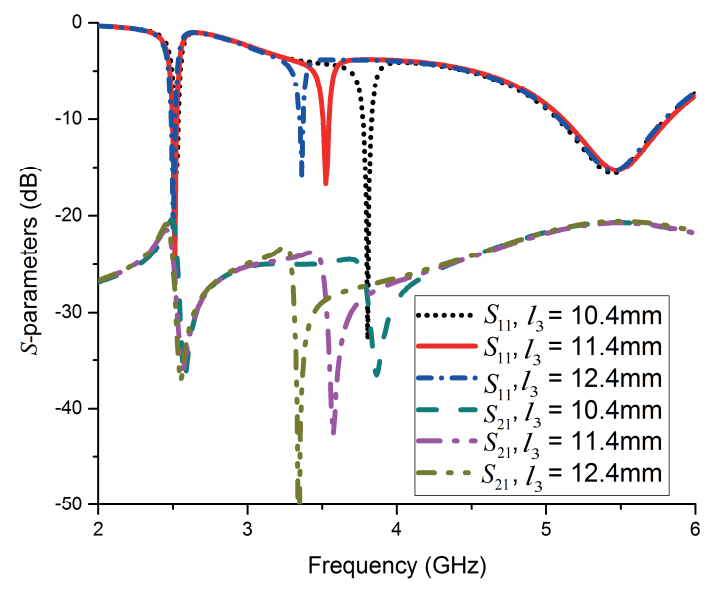

(c)

Fig. 3. Simulated $S$-parameters: (a) different values of $l_{1}$ for single-band antenna (see Fig. 2(a)), (b) different values of $l_{2}$ for dual-band antenna (see Fig. 2(b)), (c) different values of $l_{3}$ for tri-band antenna (see Fig. 2(c)).

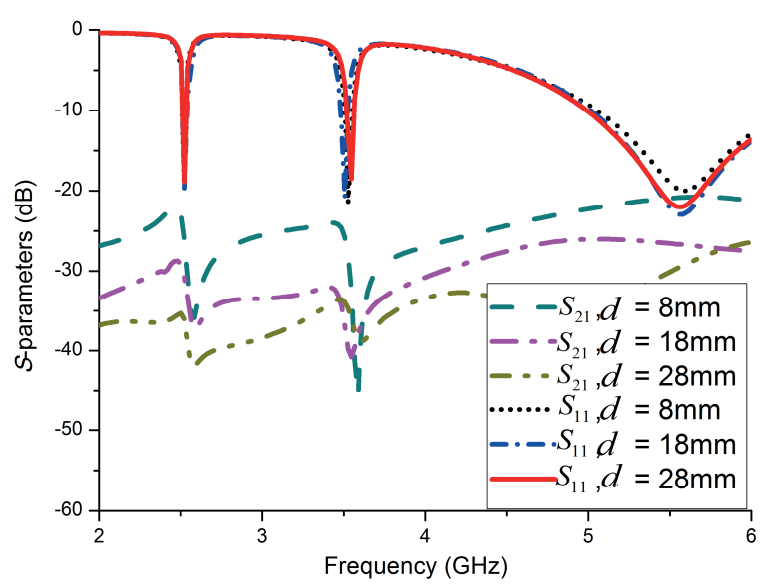

Fig. 4. Simulated $S$-parameters with different values of $d$.

posed antenna at 2.4, 3.5 and 5.5 GHz are given in Fig. 5. Fig. 5(a) shows the current distribution at $2.4 \mathrm{GHz}$ of the tri-band antenna. Note that the currents mainly flow along the edge of the rectangular slot and the edge of the loaded rectangular strip. Obviously, the current path of the $2.4 \mathrm{GHz}$ band is formed owing to the existence of the loaded rectangular strip. This is the reason why the center frequency of the $2.4 \mathrm{GHz}$ band can be adjusted by changing the parameter $l_{2}$. It is observed in Fig. 5(b) that the currents focus on the introduced L-shaped slot, which means the presence of the L-shaped slot leads to the $3.5 \mathrm{GHz}$ resonance mode. Similarly, the $3.5 \mathrm{GHz}$ band can be tuned by choosing the parameter $l_{3}$. Fig. 5(c) presents the current distribution at $5.5 \mathrm{GHz}$. We can find that the currents mainly distribute around the area from the open end of the rectangular slot to the shorted via hole. Therefore, the $5.5 \mathrm{GHz}$ resonance mode can be adjusted by changing the microstrip feeding position $\left(l_{1}\right)$. It can also be seen in Fig. 5 that only a small amount of currents exist on the shared ground plane, which denotes that the orthogonal arrangement of the two antenna elements can provide high port-to-port isolation. 


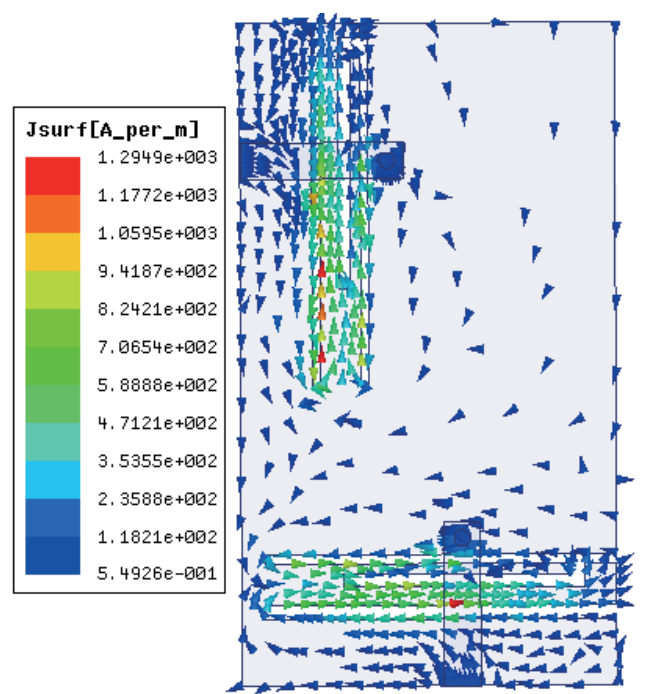

(a)

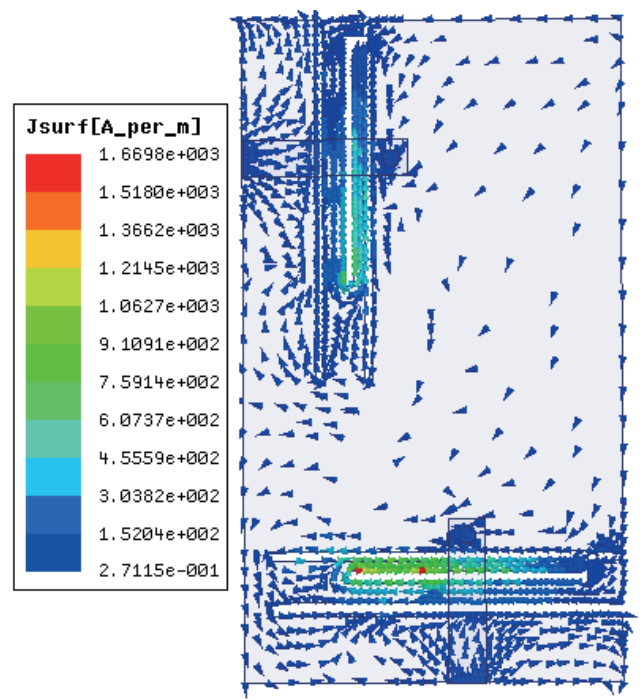

(b)

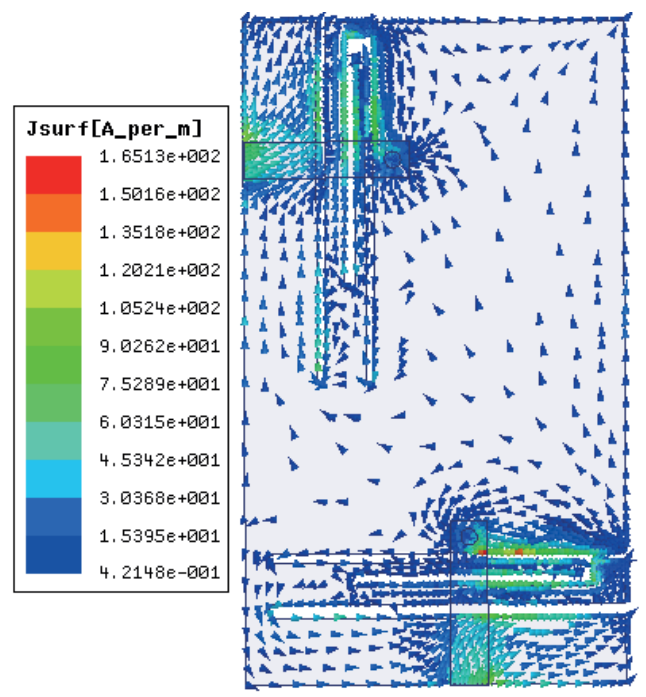

(c)

Fig. 5. Currents distribution of the proposed antenna: (a) at $2.4 \mathrm{GHz}$, (b) at $3.5 \mathrm{GHz}$, (c) at $5.5 \mathrm{GHz}$.

\section{Results and Discussion}

Based on the designed structures, a prototype antenna is fabricated and measured. The photograph of the fabricated tri-band MIMO antenna is shown in Fig. 6. The simulated and measured S-parameters for our proposed triband MIMO antenna are shown in Fig. 7. It is observed that three bands centered at $2.4,3.5$, and $5.5 \mathrm{GHz}$ are obtained. It can be seen that wider bandwidth is obtained in measurement compared to simulation. That means the fabricated antenna possesses a lower Q-value than the simulation model. This is mainly due to the loss tangent of FR4 actually used in the fabricated antenna is larger than that used in simulation. Fig. 7 also shows that the isolations between the two ports are larger than $22 \mathrm{~dB}$ within the whole operating bands. High isolation is achieved, which is mainly due to the orthogonal configurations of the two elements.

The measured radiation patterns are plotted in Fig. 8 and 9 at frequencies of 2.4, 3.5, and 5.5 GHz of the MIMO antenna. In measurement, one port is excited, and the other port is terminated by a $50 \mathrm{Ohm}$ matching load. Nearly omnidirectional radiation patterns are observed in the $\mathrm{H}$ -

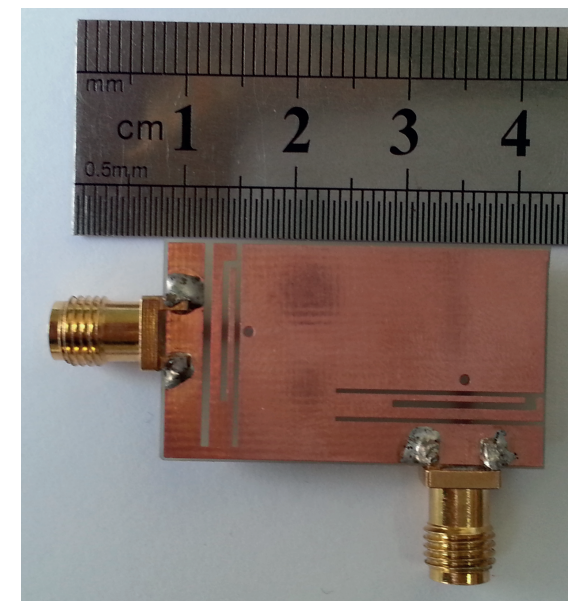

Fig. 6. Photograph of the fabricated tri-band MIMO antenna.

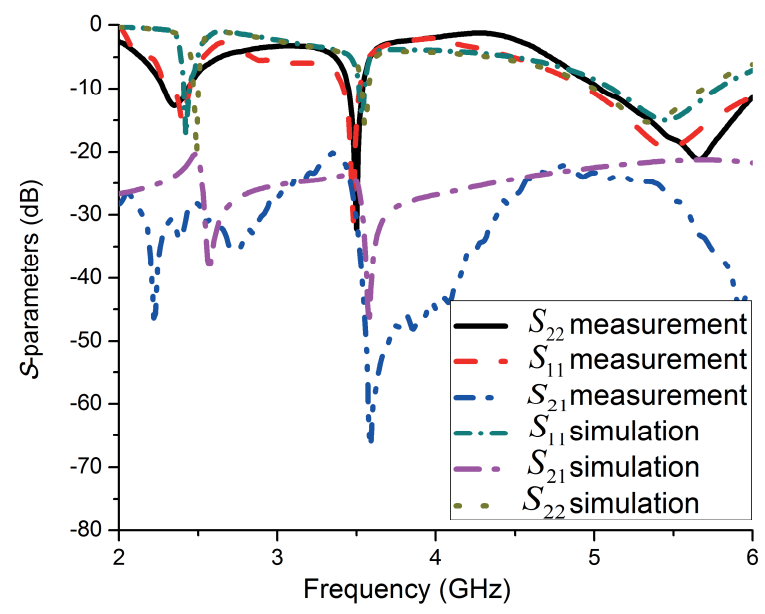

Fig. 7. Simulated and measured $S$-parameters of the proposed tri-band MIMO antenna. 
plane ( $y-z$ plane of port 1 and $x-z$ plane of port 2, respectively) of both ports at these three frequencies. For the Eplane ( $x-z$ plane of port 1 and $y-z$ plane of port 2), dipolelike radiation patterns are obtained. It may be noted that the patterns of the E-plane deteriorate as the frequency increases. The reason is that as the frequency increases, the electrical size of our proposed MIMO antenna increases as well. Hence, the antenna radiation characteristic is much sensitive to antenna physical size at high frequency. From the results, we can find that pattern diversity can be obtained as the patterns for the two ports at the same plane are quite different from each other. For example, as mentioned above, the copolarization radiation pattern in the $y-z$ plane for port 1 at $3.5 \mathrm{GHz}$ is nearly omnidirectional. However, for port 2, the copolarization radiation pattern in the $y-z$ plane is Figure-8-like shape. These differences enhance the pattern diversity of the proposed antenna. From these figures, it can also be seen that the cross polarization in the E-plane is much higher than that in the H-plane, and even close to $-10 \mathrm{~dB}$ at some angles. However, as the radiation patterns of the coplanar and cross polarization are uncorrelated [13], dual polarization of our proposed antenna can still be achieved. Therefore, we can conclude that the polarizations for the proposed two elements are quite orthogonal to each other, and good pattern diversity performance is achieved.

The measured peak gains of the proposed tri-band MIMO antenna excited from the two ports are shown in Fig. 10. As the proposed antenna has a small size, the antenna gain is not high. The antenna efficiency is also calculated. The antenna efficiency is above $70 \%$ across all the triple bands. It should be pointed out that high antenna efficiency can be obtained if we select a substrate with low dielectric loss.

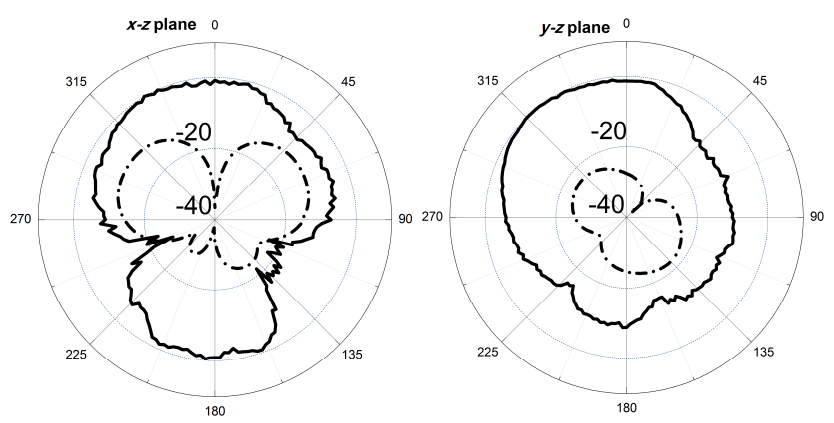

(a)

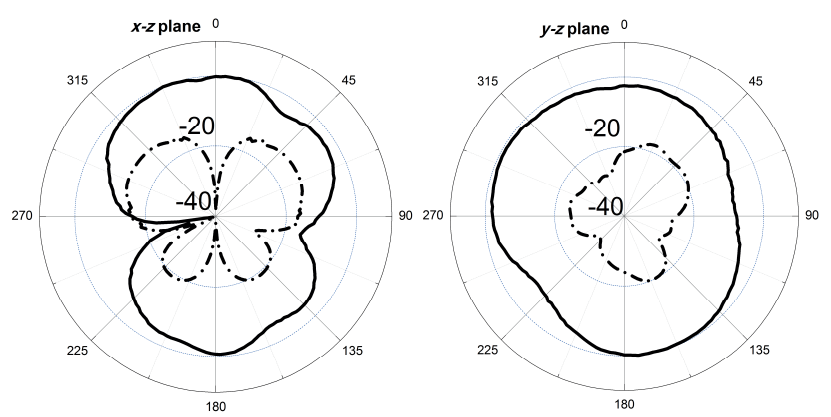

(b)

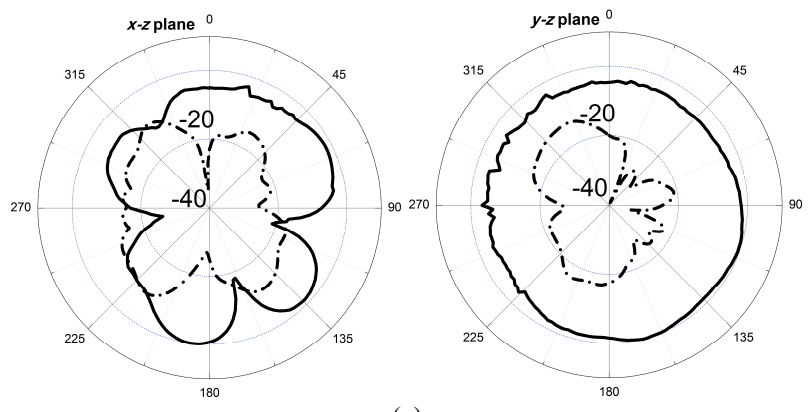

(c)

Fig. 8. The measured radiation patterns of the proposed antenna fed through port 1: (a) at $2.4 \mathrm{GHz}$, (b) at 3.5 $\mathrm{GHz},(\mathrm{c})$ at $5.5 \mathrm{GHz}$ (—co-polar, - - - cross-polar).

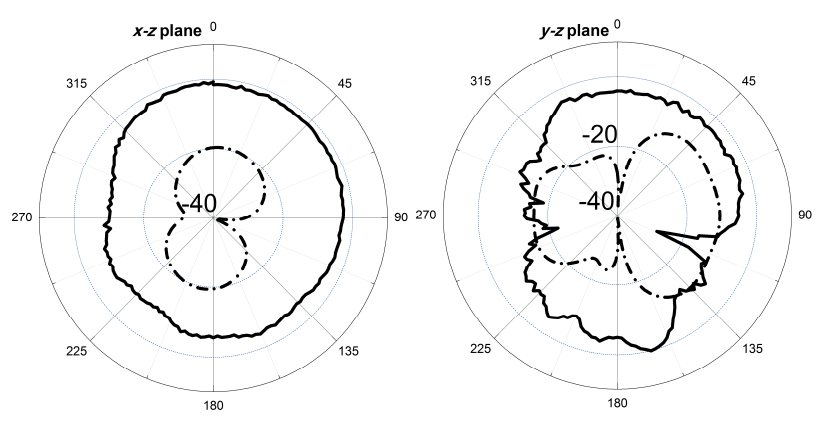

(a)

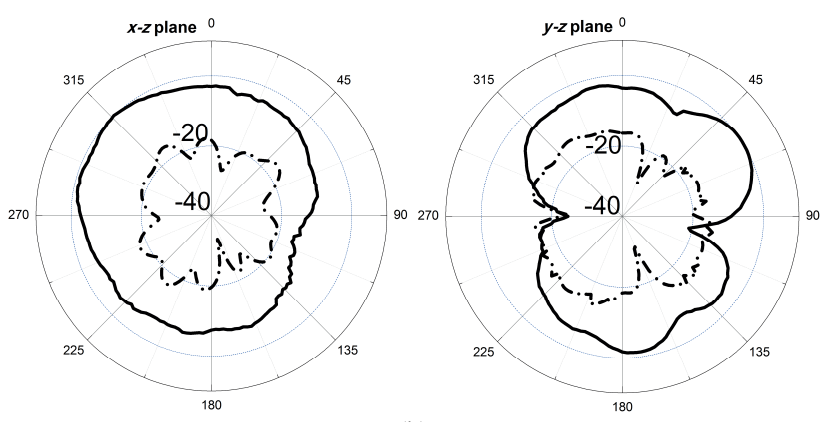

(b)

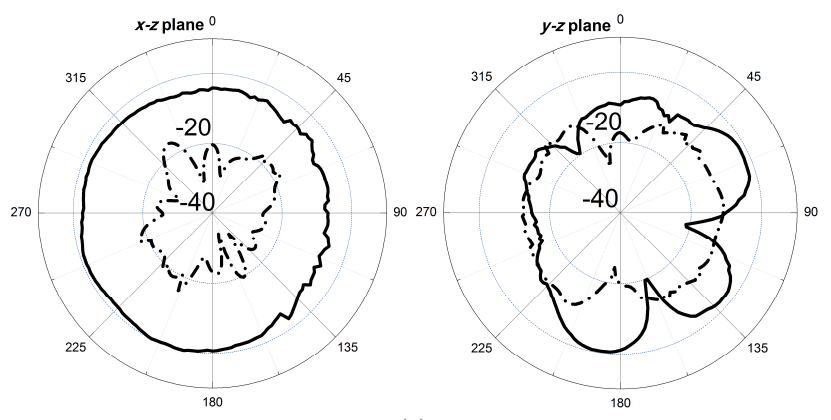

(c)

Fig. 9. The measured radiation patterns of the proposed antenna fed through port 2: (a) at $2.4 \mathrm{GHz}$, (b) at 3.5 $\mathrm{GHz}$, (c) at $5.5 \mathrm{GHz}$ (_ co-polar, - - - cross-polar).

In addition, the envelope correlation coefficient ECC is an important parameter to evaluate the diversity performance of antennas. ECC of two elements MIMO system can be calculated by formula (1) in [8]. For the sake of brevity, only the calculated result is presented. The ECC for our proposed tri-band MIMO antenna is below 0.09 over the 


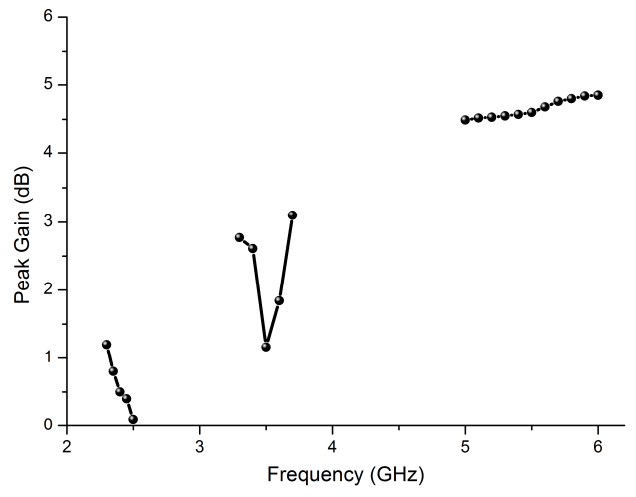

(a)

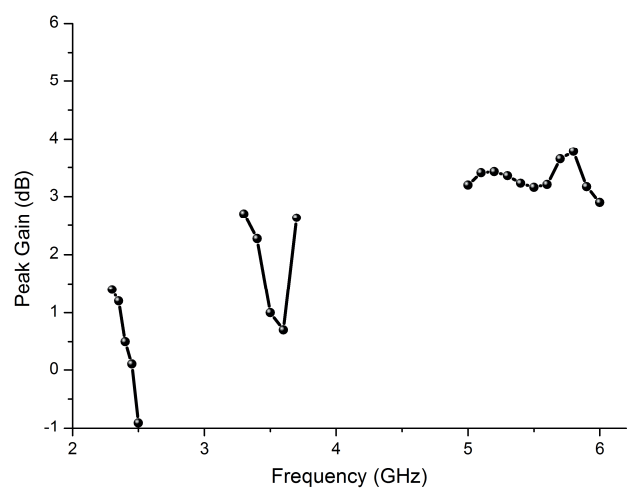

(b)

Fig. 10. The measured antenna gain against frequency: (a) for port 1 , (b) for port 2 .

whole operating band, satisfying the criteria of low correlation $(\mathrm{ECC}<0.5)$, which indicates that our proposed antenna has a good diversity performance.

Note that though the two elements of the proposed antenna are closely separated by a distance $d$ of $8 \mathrm{~mm}$ $(0.064 \lambda, \lambda$ is the free space wavelength at $2.4 \mathrm{GHz})$ for discussion in this paper, the port-to-port isolation is high enough for MIMO application. In most practical applications, the system circuit board has a much larger dimension, thus, mutual coupling can be further reduced and higher isolation can be obtained. In addition, the proposed antenna (two elements) can be easily extended to four elements MIMO system. That is, the elements of four-element MIMO antenna arrays can be placed in the four corners of planar substrate board orthogonally with each other.

\section{Conclusion}

A compact tri-band printed MIMO antenna suitable for WLAN/WiMAX applications is proposed. The proposed MIMO antenna consists of two orthogonal elements with separation of $0.064 \lambda$ at $2.4 \mathrm{GHz}$, and the whole antenna size is $19 \times 33 \mathrm{~mm}^{2}$. The isolation between the two ports is greater than $22 \mathrm{~dB}$ in the entire operating bands. The proposed design can provide good diversity performance. With small size, simple structure, low envelope correlation, and high isolation, the presented antenna is a good candidate for multiband MIMO applications.

\section{References}

[1] MEHDIPOUR, A., SEBAK, A., TRUEMAN, C. W., DENIDNI, T. A. Compact multiband planar antenna for $2.4 / 3.5 / 5.8-\mathrm{GHz}$ wireless applications. IEEE Antenna and Wireless Propagation Letters, 2012, vol. 11, p. 144-147. DOI: 10.1109/LAWP.2012.2185915

[2] CHANG, T.-H., KIANG, J.-F. Compact multi-band H-shaped slot antenna. IEEE Transactions on Antennas and Propagation, 2013, vol. 61, no. 8, p. 4345-4349. DOI: 10.1109/TAP.2013.2262666

[3] WEN, R. Compact planar triple-band monopole antenna based on a single-loop resonator. Electronics Letters, 2013, vol. 49, no. 15, p. 916-918. DOI: 10.1049/el.2013.1915

[4] JAW, J. L., CHEN, F.-S., CHEN, D.-F. Compact dual-band CPWfed slotted patch antenna for $2.4 / 5 \mathrm{GHz}$ WLAN operation. Journal of Electromagnetic Waves and Applications, 2009, vol. 23, p. 1947 to 1955 . DOI: $10.1163 / 156939309789932584$

[5] BEIGI, P., NOURINIA, J., ZEHFOROOSH, Y., MOHAMMADI, B. A compact novel CPW-fed antenna with square spiral-patch for multiband applications. Microwave and Optical Technology Letters, 2015, vol. 57, no. 1, p. 111-115. DOI: 10.1002/mop.28783

[6] SU, C. M., CHEN, H. T., WONG, K. L. Printed dual-band dipole antenna with U-slotted arms for $2.4 / 5.2 \mathrm{GHz}$ WLAN operation. Electronics Letters, 2002, vol. 38, no. 22, p.1308-1309. DOI: 10.1049/el.20020919

[7] ABDALLA, M. A., IBRAHIM, A. A. Compact and closely spaced metamaterial MIMO antenna with high isolation for wireless applications. IEEE Antenna and Wireless Propagation Letters, 2013, vol. 12, p. 1452-1455. DOI: 10.1109/LAWP.2013.2288338

[8] CUI, S., LIU, Y., JIANG, W., GONG, S. X. Compact dual-band monopole antennas with high port isolation. Electronics Letters, 2011, vol. 47, no. 10, p. 579-580. DOI: 10.1049/el.2010.3603

[9] CHIU, C. Y., YAN, J. B., MURCH, R. D. Compact three-port orthogonally polarized MIMO antennas. IEEE Antenna and Wireless Propagation Letters, 2007, vol. 6, p. 619-622. DOI: 10.1109/LAWP.2007.913272

[10] LIU, L., CHEUNG, S. W., YUK, T. I. Compact MIMO antenna for portable devices in UWB applications. IEEE Transactions on Antennas and Propagation, 2013, vol. 61, no. 8, p. 4257-4264. DOI: $10.1109 /$ TAP.2013.2263277

[11] KARIMIAN, R., ORAIZI, H., FAKHTE, S., FARAHANI, M. Novel F-shaped quad-band printed slot antenna for WLAN and WiMAX MIMO systems. IEEE Antenna and Wireless Propagation Letters, 2013, vol. 12, p. 405-408. DOI: 10.1109/LAWP.2013.2252140

[12] ALI NEZHAD, S. M., HASSANI, H. R. A novel tri-band Eshaped printed monopole antenna for MIMO application. IEEE Antenna and Wireless Propagation Letters, 2010, vol. 9, p. 576 to 579. DOI: 10.1109/LAWP.2010.2051131

[13] LI, Y., ZHANG, Z., CHEN, W., FENG, Z., ISKANDER, M. F. A dual-polarization slot antenna using a compact CPW feeding structure. IEEE Antenna and Wireless Propagation Letters, 2010, vol. 9, p. 191-194. DOI: 10.1109/LAWP.2010.2044865

\section{About the Authors ...}

Jiawei ZANG was born in Shandong Province, China. He received his B. Eng. degree in Electric Science and Technology from Beijing Inst. of Technology, Beijing, China, in 2014. He is currently working toward the $\mathrm{Ph}$. D. degree at Beijing Inst. of Technology. His research interests include multiband antennas and MIMO antennas. 
Xuetian WANG was born in Jiangsu Province, China. He received the B. S and $\mathrm{Ph}$. D. degrees in Electronic Engineering from Beijing Inst. of Technology, Beijing, China, in 1986 and 2002, respectively. He is currently a full Pro- fessor with the School of Information and Electronics, Beijing Inst. of Technology. His current research interests include antenna theory and applications, millimeterwave imaging, EMC, and terahertz radar.

\section{RADIOENGINEERING REVIEWERS}

\section{June 2015, Volume 24, Number 2}

- ADDACI, R., Insight SiP, France

- AgATONOVIC, M., University of Nis, Serbia

- ALA-LAURINAHO, J., Aalto University, Finland

- ARRIBAS, J., Centre Tecnologic de Telecomunicacions de Catalunya, Spain

- BAJER, J., University of Defense, Brno, Czechia

- BARBUTO, M., Roma Tre University, Italy

- BARTOLIC, J., University of Zagreb, Croatia

- BARUFFA, G., University of Perugia, Italy

- BARTIK, H., Czech Technical University in Prague, Czechia

- BENETOS, E., City University London, UK

- BEZPALEC, P., Czech Technical University in Prague, Czechia

- BIOLEK, D., University of Defense, Brno, Czechia

- CAPEK, M., Czech Technical University in Prague, Czechia

- CHANDRA, A., National Institute of Technology Durgapur, India

- COSTANZO, S., University of Calabria, Italy

- DRAHANSKY, M., Brno Univ. of Technology, Czechia

- DVORAK, V., Brno Univ. of Technology, Czechia

- EICHLER, J., Czech Technical University in Prague, Czechia

- FORERO, M.G., Cardiff University, UK

- FRENI, A., University of Florence, Italy
- FRYZA, T., Brno Univ. of Technology, Czechia

- GABARDA, S., CSIC, Spain

- GOTTHANS, T., Brno University of Technology, Czechia

- GREINER, T., Pforzheim University, Germany

- GUARDiOlA, M., Universitat Pompeu Fabra, Spain

- HAGARA, M., Slovak University of Technology, Bratislava, Slovakia

- HAZDRA, P., Czech Technical University in Prague, Czechia

- HOFFMANN, K., Czech Technical University in Prague, Czechia

- HORNG, J.-W., Chung Yuan Christian University, Taiwan

- HORVATH, P., Budapest University of Technology and Economics, Hungary

- HUBERT, S., Université catholique de Louvain, Belgium

- HUdCOVA, L., Brno Univ. of Technology, Czechia

- CHAIMOOL, S., King Mongkut's University of Technology North Bangkok, Thailand

- JELINEK, L., Czech Technical University in Prague, Czechia

- KABOUREK, V., Czech Technical University in Prague, Czechia

- KADLEC, P., Brno Univ. of Technology, Czechia

- KALAYCIOGLU, A., Ankara University, Turkey

- KAMENCAY, P., University of Zilina, Slovakia 
- KARWOWSKI, A., Silesian University of Technology, Poland

- KASAL, M., Brno Univ. of Technology, Czechia

- KHATEB, F., Brno Univ. of Technology, Czechia

- KRACEK, J., Czech Technical University in Prague, Czechia

- KRATOCHVIL, T., Brno Univ. of Technology, Czechia

- KUBANEK, D., Brno Univ. of Technology, Czechia

- KUBICEK, M., Brno University of Technology, Czechia

- KUFA, M., Brno Univ. of Technology, Czechia

- KYRIACOU, G.A., Democritus University of Thrace, Greece

- LACIK, J., Brno University of Technology, Czechia

- LAKKUNDI, V., Patavina Technologies, Italy

- LAZARO, A., Universitat Rovira i Virgili, Spain

- LI, Y., Harbin Engineering University, China

- LUO, CH. M., University of Electronic Science and Technology of China, China

- MA, Z., University of Leuven (KU), Belgium

- MACHAJ, J., University of Zilina, Slovakia

- MARCHEVSKY, S., Technical University of Kosice, Slovakia

- MARSALEK, R., Brno Univ. of Technology, Czechia

- MATSUNO, H., KDDI R\&D Laboratories. Inc., Japan

- MAZANEK, M., Czech Technical University in Prague, Czechia

- MIKULASEK, T., Brno University of Technology, Czechia

- MORAVEK, O., Czech Technical University in Prague, Czechia

- MOSCATO, S., University of Pavia, Italy

- NEMECEK, J., University of Defense, Czechia

- OCHODNICKY, J., Armed Forces Academy, Slovakia

- OZEN, A., Nuh Naci Yazgan University, Turkey

- PETRZELA, J., Brno University of Technology, Czechia

- PHROMPICHAI, S., Mahanakorn University of Technology, Thailand

- PINCHAS, M., Ariel University Center of Samaria, Israel

- POLAK, L., Brno University of Technology, Czechia

- POLIVKA, M., Czech Technical University in Prague, Czechia

- POLIAK, J., Brno University of Technology, Czechia
- POMENKOVA, J., Brno Univ. of Technology, Czechia

- PRIBIL, J., Slovak Academy of Sciences, Slovakia

- PRIBILOVA, A., Slovak University of Technology, Bratislava, Slovakia

- PRIETO, A.F., Universidad de Sevilla, Spain

- PUSKELY, J., Brno Univ. of Technology, Czechia

- RAHIMIAN, A., University of Birmingham, UK

- RAIDA, Z., Brno Univ. of Technology, Czechia

- ROUABAH, K., University of Bordj Bou Arreridj, Algeria

- ROKA, R., Slovak University of Technology, Bratislava, Slovakia

- SACHS, J., Technische Universitaet Ilmenau, Germany

- SALAZAR, A., Universidad Politecnica Valencia, Spain

- SEBESTA, J., Brno Univ. of Technology, Czechia

- SEBESTA, V., Brno Univ. of Technology, Czechia

- SIGMUND, M., Brno Univ. of Technology, Czechia

- SILVA, A., University of Aveiro, Portugal

- SIZOV, V., University of Birmingham, UK

- SlANINA, M., Brno Univ. of Technology, Czechia

- SOH, P. J., University Malaysia Perlis, Malaysia

- SOTNER, R., Brno Univ. of Technology, Czechia

- SPANEL, M., Brno Univ. of Technology, Czechia

- STANDER, T., University of Pretoria, South Africa

- SVANDA, M., Czech Technical University in Prague, Czechia

- TAMAGNONE, M., EPFL, Switzerland

- TOMASIN, S., University of Padova, Italy

- TRALIC, D., University of Zagreb, Croatia

- UlOVEC, K., Czech Technical University in Prague, Czechia

- URICAR, T., Czech Technical University in Prague, Czechia

- VARGIC, R., Slovak University of Technology, Bratislava, Slovakia

- VISCOR, I., Institute of Scientific Instruments of the ASCR, Czechia

- VLCEK, C., University of Defense, Brno, Czechia

- ZENTNER, R., University of Zagreb, Croatia

- ZHANG, J., PLA University of Science and Technology, China

- ZHAO, B., Tsinghua University, China

- ZHENG, X., University of Leuven (KU), Belgium

- ZVANOVEC, S., Czech Technical University in Prague, Czechia 